\title{
Women's Experiences of Group Prenatal Care
}

\author{
Gina Novick ${ }^{1}$, Lois S. Sadler ${ }^{1}$, Holly Powell Kennedy ${ }^{1}$, Sally S. Cohen ${ }^{2}$, Nora E. Groce ${ }^{3}$, and \\ Kathleen A. Knafl ${ }^{4}$ \\ ${ }^{1}$ Yale University, New Haven, Connecticut, USA \\ ${ }^{2}$ University of New Mexico, Albuquerque, New Mexico, USA \\ 3 University College London, London, United Kingdom \\ ${ }^{4}$ University of North Carolina at Chapel Hill, North Carolina, USA
}

\begin{abstract}
Group prenatal care (GPNC) is an innovative alternative to individual prenatal care. In this longitudinal study we used ethnographic methods to explore African American and Hispanic women's experiences of receiving GPNC in two urban clinics. Methods included individual, indepth, semistructured interviews of women and group leaders in GPNC, participant observation of GPNC sessions, and medical record review. GPNC offered positive experiences and met many of the women's expressed preferences regarding prenatal care. Six themes were identified, which represented separate aspects of women's experiences: investment, collaborative venture, a social gathering, relationships with boundaries, learning in the group, and changing self. Taken together, the themes conveyed the overall experience of GPNC. Women were especially enthusiastic about learning in groups, about their relationships with group leaders, and about having their pregnancyrelated changes and fears normalized. There were also important boundaries on relationships between participants, and some women wished for greater privacy during physical examinations.
\end{abstract}

\section{Keywords}

African American; health care, users' experiences; Latino / Hispanic people; midwifery; pregnancy; women's health

\begin{abstract}
Women's experiences of prenatal care are poorly understood. This is surprising because, with 4.3 million births in the United States in 2007, for example (Hamilton, Martin, \& Ventura, 2009), prenatal care is a leading reason for ambulatory care visits (Schappert \& Rechsteiner, 2008). Although there has been extensive research on pregnancy outcomes as well as issues related to access to and adequacy of prenatal care, there has been little attention devoted to the experiences of the women who receive this care. Nevertheless, the experience of prenatal care is mixed for many women. In an integrative review of 36 articles published between 1997 and 2007 on women's experience of prenatal care, Novick (2009) reported that some women had respectful, individualized care with providers they trusted, that included receiving information, social support, ancillary services, and that they had continuity with a primary prenatal clinician and coordination of care. However, other women reported long waits and/or rushed visits, rude treatment by staff and professionals,
\end{abstract}

Corresponding Author: Gina Novick, Yale University School of Nursing, 100 Church St. South, PO Box 9740, New Haven, CT 06536-0740, USA gina.novick@yale.edu.

Declaration of Conflicting Interests

The authors declared no conflicts of interest with respect to the authorship and/or publication of this article. 
and mechanistic care that did not meet their needs for advice or support. Women desired care that had reasonable waiting times and unhurried visits, provided information tailored to their needs, was comprehensive and coordinated, and welcomed their significant others. They also placed great importance on their relationships with clinicians and preferred having a single prenatal provider with whom they could have an informal, personal relationship. Finally, women wanted help in becoming more active participants in their care and the opportunity to meet with other pregnant women.

One approach to prenatal care with many features that might address women's needs is group prenatal care (GPNC). GPNC is being implemented increasingly across the United States as an alternative to individual care and there is an emerging body of literature on this innovative model (Baldwin, 2006; Bloom, 2005; Carlson \& Lowe, 2006; Grady \& Bloom, 2004; Hackley, Applebaum, Wilcox, \& Arevalo, 2009; Ickovics et al., 2007; Ickovics et al., 2003; Kennedy et al., 2009; Kershaw, Magriples, Westdahl, Rising, \& Ickovics, 2009; C. Klima, 2009; C. S. Klima, 2003; Massey, Risser, \& Ickovicks, 2006; Mooney, Russell, Prairie, Savage, \& Weeks, 2008; Novick, 2004; Rising, 1998; Rising, Kennedy, \& Klima, 2004; Robertson, Aycock, \& Darnell, 2009; Stemig \& Stemig, 2008; Stevens, Iida, \& Ingersoll, 2007; Walker \& Worrell, 2008). Yet, despite the fact that a central aim of this model is to provide women-centered care, there are relatively few data on women's experience of GPNC. In this article, we present findings from an in-depth, longitudinal study of women's experience of GPNC.

\section{Group Prenatal Care}

Group prenatal care is an innovative approach to prenatal care that offers care to women in groups. The predominant model of GPNC is CenteringPregnancy (Centering). This model has been discussed in detail elsewhere (Novick, 2004, 2009; Rising, 1998; Rising et al., 2004), but will be described briefly here. Centering provides prenatal care to groups of 8-12 women of similar gestational age. After an initial individual obstetrical history and physical examination, women enter group care. In many settings, significant others also attend. When women and their guests arrive at the group, they are taught to take their own blood pressures, weigh themselves, and record the findings. Individual prenatal examinations are provided by a clinician, often on a mat on the floor behind a privacy screen. After these examinations, participants sit together in a circle and engage in group discussion, which covers a wide range of pregnancy-related health topics. Although a CenteringPregnancy handbook provides written materials and broad guidelines for session content, group leaders ideally use a nondidactic, facilitative approach to customize topics to participants' interests. Partners or family members may attend groups and snacks can be provided. Throughout the course of pregnancy, there are typically 8 to 10 Centering sessions, each lasting 1.5 to 2 hours. More than 300 sites currently conduct Centering groups (Rising, 2009). The Centering Health Institute develops materials for implementing CenteringPregnancy and conducts a site approval process (Centering Healthcare Institute, 2009).

Outcomes of Centering have been compared with individual prenatal care in several research studies. In five nonexperimental studies with nonequivalent groups, women in Centering had fewer emergency department visits (Rising, 1998), increased breastfeeding rates (Grady \& Bloom, 2004; Klima, 2009), more prenatal visits, greater prenatal weight gain (Klima, 2009), and comparable or improved rates of low birth weight and prematurity (Bloom, 2005; Robertson et al., 2009). Ickovics et al. (2003) reported results of a matched cohort study in which women receiving Centering had longer gestations, infants with heavier birth weights, and increased birth weights of preterm infants $(n=458)$. Finally, in a multisite randomized controlled trial $(n=1,047)$, no difference in birth weight was demonstrated; however, women in Centering had a $33 \%$ reduced risk of preterm birth (with 
an even stronger effect in African American women), reduced likelihood of suboptimal prenatal care, and higher rates of breastfeeding (Ickovics et al., 2007). Within this trial, women assigned to GPNC with an HIV-prevention component were less likely to be pregnant at 6 months postpartum, and demonstrated increased condom use and decreased unprotected sexual intercourse compared with individual care and GPNC controls. However, there was no difference in incidence of gonorrhea, chlamydia, or repeat pregnancy at 12 months postpartum (Kershaw et al., 2009). When findings from these studies are considered collectively, it appears that Centering might have outcomes comparable with or even superior to individual care.

Women's experiences of GPNC were explored in four studies. In two of these, satisfaction with Centering was compared with individual care. The other two studies had qualitative, retrospective designs. Baldwin (2006) found no difference in satisfaction scores in nonequivalent groups $(n=98)$, whereas Ickovics and colleagues (2007) reported significantly increased satisfaction with GPNC in a randomized controlled trial $(n=1,047)$. However, there are important limitations regarding the use of patient satisfaction to measure experience, including the tendency toward high reported levels of satisfaction, acquiescence bias, instruments that fail to account for the unique features of prenatal care, lack of agreement for proper timing of measurements, and recall bias or confounding related to the birth experience for postpartum assessments (Novick, 2009).

Klima (2009) reported that women enjoyed sharing their pregnancy experiences with others who had similar experiences and concerns $(n=5)$. Kennedy and colleagues (2009) conducted interviews with 234 women who were randomized to GPNC and individual care. Most women were enthusiastic about GPNC, felt they had learned a lot, and felt that they were not alone in experiencing discomforts and worries. They also liked learning from other women and having clinician continuity. Some women in GPNC, however, felt rushed during examinations, needed more privacy, or wanted more individual time with providers. In contrast, women in individual care expressed frustration with lack of clinician continuity and accessibility. They felt that sometimes care was inflexible and rushed, and that after sustaining long waits, their "needs were not being heard," or that staff "brushed you off" (p. 180). Thus, GPNC might be safe and effective, and might also address many of women's needs for care during pregnancy. To our knowledge, however, at the time of this writing there are no published longitudinal, in-depth studies of women's experiences of GPNC. The research reported here addresses this gap.

The specific aims of this study were to describe women's experiences of group prenatal care, describe the activities and interactions of participants in group prenatal care, and explore factors that might influence the experiences of group prenatal care, including women's health status and social, cultural, and health care environments. In this article we present findings related primarily to the first aim, although data collected for the second and third aims provide some context for understanding women's experiences.

\section{Methods}

The approach for this study was interpretive description, in which multiple data collection techniques and critical examination of data to generate conceptual linkages and holistic interpretations of complex clinical processes are used (Caelli, Ray, \& Mill, 2003; Kearney, 2001; Sandelowski, 2000, 2010; Thorne, 2008; Thorne, Reimer-Kirkham, \& O’FlynnMagee, 2004) 


\section{Setting}

The study was conducted at two urban clinics in two northeastern states, one in a hospital complex and the other in a freestanding community health center in a low-income neighborhood. Both clinics served mostly African American or Hispanic women who were receiving Medicaid, were income-eligible for Medicaid, or were uninsured. In one setting, women had continuity with the same prenatal care provider, regardless of type of prenatal care selected. In both sites, births were attended by several clinicians who shared call on a rotating basis. The prenatal care clinicians for the observed groups were certified nursemidwives (CNMs). In both settings, the CenteringPregnancy model and educational materials were used to provide GPNC. Neither setting had obtained prior Centering Healthcare Institute site approval; this process was developed approximately when data collection for this study began (Centering Healthcare Institute, 2009; Rising, 2009).

\section{Sample}

Participants in four English-speaking Centering groups were studied, two groups in each clinic. These groups were naturally composed as part of routine care offered in these clinics. The principal participants were 21 pregnant women who consented to individual interviews and medical record reviews (one interview participant declined record review). Additional participants were 18 subjects of participant observation (in group sessions), including 8 pregnant women who declined interviews, 6 guests ( 3 men and 3 women), 2 CNM group leaders (one in each clinic), and 2 medical assistants. Institutional Review Board (IRB) approval for one site did not allow significant others or non-CNM professionals in GPNC to participate, so they are not included in sample numbers. Children attending GPNC as guests were not research participants.

Eighteen of the 21 principal participants were African American and 3 were Hispanic; 19 women were single and 2 were married. The mean age was 21.6 years (range 17 to 31 ), and the women's education ranged from grade school to some college. Study participants from the two sites did not differ in mean age, marital status, or mean years of education. The mean number of sessions attended by all pregnant participants was 4.3 ; the mean number of sessions attended by the principal participants was 5.4.

\section{Data Collection}

Ethics approval was obtained from the Yale University School of Nursing Human Subjects Research Review Committee and from IRBs at the clinical sites prior to data collection. The first author collected data from March, 2007 through September, 2008. At the first GPNC session, an overview of the study was provided by the first author, who then stepped out of the room to allow group members to decide whether to allow participant observation. Women were met with and were consented individually. Principal participants received a $\$ 20$ gift card for each interview, plus a $\$ 20$ bonus for completing multiple interviews. All pregnant women received a small baby gift. The four data collection procedures included 45 interviews of 21 women during pregnancy and postpartum, participant observation of 31 out of 35 total sessions conducted in four GPNC series, review of medical record data for 20 women, and seven interviews of 2 group leaders.

The objective of interviews with principal participants was to gain understanding of women's perspectives on their experiences of GPNC. Questions were initially broad to permit discovery of new understandings, and probing was used to explore responses in greater detail. The original plan, to conduct two interviews during pregnancy and one postpartum, was modified owing to late entry into groups by many participants and the difficulty of contacting women who had irregular phone service. Eight participants had three interviews each, 8 had two interviews, and 5 had one interview. Multiple attempts were 
made to schedule interviews with women who remained in GPNC, as well as with women who had discontinued GPNC. Group leaders were interviewed to gain their perspectives on events and interactions during sessions, on women's experiences, and on institutional factors that facilitated or impeded conducting groups. Group leaders were interviewed at least once during each series and after the series ended.

All study participants were offered the choice of in-person or telephone interviews. Although it is sometimes thought that telephone interviews yield less valid data than inperson interviews, there is little evidence to support this belief (Novick, 2008). Thirty-nine women's interviews (84\%) were conducted via telephone. All formal interviews were recorded digitally, and field notes were taken. Interview duration was longest during postpartum interviews, because women had gained experience with GPNC and familiarity with the interviewer, and because women told their birth stories as well as discussing their experiences with GPNC.

The objectives of participant observation were to describe the activities and interactions in groups, the evolution of groups over time, the roles of group leaders, and to understand individual interview data in the context of what was taking place in the group. The first author's role as participant observer varied with group activities to minimize impact on group dynamics. Field notes were recorded during interviews; abbreviated field notes were also recorded during sessions and expanded later. Demographic and health data were used to describe the study population and provide background for understanding individual women's pregnancies and their experiences of GPNC. These data were collected from medical records of principal participants prenatally and postpartally, using a data collection form developed for this project.

\section{Data Analysis}

In the overall study, we examined women's experiences of GPNC from the perspectives of both the women and the GPNC leader, as well as how these experiences related to women's personal lives and health care settings. In the current analysis, we describe the central aspects of women's experiences of GPNC.

Analysis was inductive and began during data collection to allow modifications of study design (Miles \& Huberman, 1994; Patton, 2002). The unit of analysis was the pregnant participant in GPNC. Within-case and across-case analysis strategies allowed identification of significant elements in participants' accounts and of changes over time, as well as the development and comparison of themes within and across individuals, GPNC series, and sites (Ayres, Kavanaugh, \& Knafl, 2003). Individual interviews were transcribed and entered into ATLAS.ti computer software (version 5.5.9). An a priori, or start list of codes (Miles \& Huberman, 1994) was derived from the study's specific aims, relevant literature, and interview guide questions. The first author then selected several interviews for variety and coded them inductively. Next, the first author integrated start and inductive codes and, along with the second author, coded several interviews to determine coding agreement. The first author then coded all interviews, searching for both explicit and implicit meanings.

After coding all interviews, the first author identified five key ideas-episodes, stories or preliminary themes-from the data. Codes relevant to these ideas were identified and data assigned to them was examined for patterns. When these ideas had been explored, data for remaining codes were then examined. Content was compared across codes to seek common ideas and to identify and refine themes. Themes were defined as patterns in the data that were prevalent, salient, and revealing of women's experiences in ways that went beyond mere description of the model. The first and second authors crosschecked themes for agreement. 
Participant health and demographic profiles were also developed from medical record and interview data; themes relevant to each woman were added to these profiles. A grid was developed to display themes by participant, permitting comparison across individuals and within and across GPNC series and sites. When themes were finalized, a prevailing typology of the experience of GPNC was identified. Profiles of each Centering series and site were also created from field notes and interview data to enhance understanding of the contexts for individual women's experiences of GPNC.

\section{Rigor}

This study was an in vivo, naturalistic study of women's experiences as part of routine care offered to women in these clinics. Data were gathered to include the perspectives of multiple women over time, enhancing trustworthiness and reducing recall bias. Collecting data from four group series in two settings balanced the ideal of variation with the smaller sample size required to conduct detailed qualitative analysis (Bernard, 2002; Marshall \& Rossman, 1999; Sandelowski, 1995), and provided sufficient data to achieve informational redundancy (Patton, 2002; Sandelowski, 1995). The researcher's participation in the groups contributed to the development of trust and rapport with study participants (Patton, 2002), yielding detailed, rich data (Bernard). This allowed a more complex understanding of social contexts of care (LeCompte \& Goetz, 1982), thereby enhancing credibility and interpretive validity (Lincoln \& Guba, 2000).

Data collection procedures were refined throughout the project, consistent with the study's "emergent, flexible design" (Patton, 2002, p. 44). Field supervision was conducted to assist the first author to reflect on the impact of her background on her interactions with participants and on her interpretive lens. Additional strategies to ensure quality included crosschecking coding and themes with the second author and maintaining a detailed audit trail (Emden \& Sandelowski, 1999; Rodgers \& Cowles, 1993).

\section{Findings}

The central finding of this research was that women enjoyed receiving their prenatal care in groups. When asked whether they would choose GPNC or individual care for a subsequent pregnancy, women overwhelmingly said without hesitation that they would choose GPNC. They also said they had fun in groups, looked forward to the next session, enjoyed sharing experiences with other women, and would recommend GPNC to other pregnant women. One participant described her overall reaction to receiving care in the group: "I love coming here. I love staying from 1:00 to 3:00. It's just a different experience, so that's probably why I have so much positive things, only because it helps."

In this section, we discuss six themes that figured prominently in women's experiences of group prenatal care. First, however, a composite picture of a group series, created from the study's multiple data sources, is presented to provide context for understanding the more detailed examination of the specific themes.

When women first joined GPNC, few knew what to expect from this unfamiliar approach to care, and therefore some women were nervous or skeptical. As each session started, women and their guests entered the group space, performed self-care (e.g., checked and recorded weight and blood pressure), then sat down on chairs arranged in a circle to await individual examinations. Examinations took approximately five minutes each, during which time the CNM reviewed individual histories, performed abdominal examinations, and ordered laboratory testing. As one woman finished her examination, she rejoined the group, and another then met with the CNM. While waiting, sometimes people sat silently; at other times, they chatted about their due dates or their baby's genders. Food and music, when 
present, contributed to a pleasant, relaxed atmosphere. Over the first few sessions, new women continued to join the group. Therefore, group size was initially small, grew midseries, and tapered off as women gave birth. Some women attended once or twice and did not return, and sometimes women brought different guests. Therefore, group membership changed throughout the series.

After completing exams, the group leader often opened discussion by asking everyone to take turns answering the same question. The question posed - and the nature of the ensuing discussion-shifted over time as pregnancies progressed, relationships developed, and women became more familiar with the group process. Group leaders responded to comments of group members, providing information and reassurance. Women also responded, sharing their experiences and offering advice. Sometimes discussion strayed from the original prompt, but group leaders viewed these digressions as important opportunities for group members to raise issues and for group leaders to address women's own concerns. Despite the often serious nature of the topics, laughter was a regular feature of group conversations. As group members became more comfortable in the group setting, they also posed their own questions, which generated additional discussion. The topics women introduced also evolved over time, although some intimate topics such as vaginal discharge or sex during pregnancy arose early on in the group process. In response to changes in the group's dynamics over the course of the series, the group leader adjusted her facilitation strategies to promote women's participation and to enhance women's ownership of the group process.

In these discussions, women learned information they wanted to know in ways that helped them to truly understand the material being covered. Group leaders were central to women's learning: they were dedicated, dynamic teachers who made learning fun, but women also learned by participating and listening to other women. Learning in this way allowed women to contemplate and implement changes in health behaviors and to feel more in control as they faced the remainder of pregnancy and the approaching birth.

Over time, most women came to feel comfortable in the group. Relationships grew, discussion topics evolved, and women learned and had fun together. Being in the group reduced women's anxiety and feelings that they were alone; however, this prevailing typology of women's experience had important variants. Attendance fluctuated, and this affected the ability of women to develop relationships. Group leaders sometimes juggled multiple roles, such as greeting women, teaching them how to perform self-care, retrieving needed materials, and conducting examinations. At times, this prevented them from being able to focus on creating a relaxed social atmosphere in the group.

Women's participation in discussion, and how they felt about people's participation (their own and others), varied widely. Some women rarely spoke; when these women also said little about GPNC in interviews it was difficult to glean their experience. However, some women who were very quiet in groups communicated their enthusiasm for GPNC during interviews, and portrayed themselves as having participated in discussions. Conversely, some women did participate actively, and expressed their disappointment in other women's limited contributions. These findings support views expressed by group leaders that engagement is not simple to gauge, and that women's level of participation does not necessarily reveal their experience. Finally, many women had entered prenatal care while experiencing profoundly difficult personal situations, but these were rarely discussed in the groups. Although relationships between participants grew over time, with women becoming increasingly comfortable sharing information with one another, these relationships had significant boundaries and there were alternative experiences to the prevailing typology of women's experience. 
This composite picture has touched on several of the major themes indentified in this study. In this section we focus closely on these themes, or major aspects of women's experiences of GPNC. These themes are investment, collaborative venture, a social gathering, relationships with boundaries, learning in the group, and changing self. Although these themes depict a common typology of experience, the existence of a prevailing pattern does not imply that it is universal. Indeed, this research found disconfirming cases, which have important implications; these are also reported.

\section{Investment: "Sitting There Taking Time Out"}

Investment refers both to women becoming invested in their groups and to women feeling invested in by other group members and the group leader. Investment began with recruitment. Almost all women had been recruited into GPNC during routine prenatal visits with their group leaders. Hearing about GPNC from a group leader that women knew helped ease their initial concerns about this unfamiliar approach to care. Women recalled being informed, while being recruited into GPNC, that GPNC was "easier" and decreased waiting, and that guests were welcome. Women tried GPNC because it was "something different"; to learn more about pregnancy, birth, and parenting; to be with other pregnant women; and to have continuity of prenatal clinician (in the one clinic that did not routinely provide this). Most women were encouraged to attend a session to see what it was like, with the option to return to individual care. This option might have been a critical recruitment tool, because many women were confused initially about the purpose and processes of GPNC. One woman worried that GPNC was a way for "DCF [Department of Children and Families] to come into my baby's life." Another woman had wondered about how physical examinations would be conducted: "I didn't know if, like they exam all the girls, like everybody's in a room. I just didn't think that'd be something I wanted to do." Caution and initial lack of investment, however, eventually gave way in these same individuals to regular attendance and enthusiastic comments. Indeed, two of these women returned after their babies were born with their partners and newborn babies to share their birth experiences with the group.

Once groups began, women's sense of investment was related to regular attendance, spending time together, and having their time respected. Women demonstrated investment by attending regularly despite numerous hurdles, such as babysitting and transportation problems. Some women were proud of their attendance, felt closer to women who attended regularly, and expressed disapproval of those who did not:

Like she's been there since Day one. We were like the first people there, and we were the last people there. The other people, they just stopped coming. Some people would miss a lot of appointments, but me and her, we were both consistent.

As women spent time together, they became more familiar and comfortable with one another. Women sometimes communicated the value of this time when they talked about "sitting," a term employed repeatedly to evoke a sense of being together informally, or "hanging out": "[I enjoyed] just sitting down and being able to experience that with somebody else." "Sitting" suggested stability, companionship, and mutual investment.

Women also felt that group leaders invested in them. Despite limited individual time, these midwives were perceived as attentive, unhurried during examinations, and available to address concerns privately. One participant explained: "Because somebody is actually like sitting there taking their time out with you, not worrying about, 'Oh, I've got this patient and that other patient." Some women, however, wished for more individual time with the clinician, a concern that was primarily expressed early in the series. Although 1.5- to 2-hour sessions initially seemed long to some women, most eventually described the duration as "enough time," and thought their time had been used "wisely." Women also appreciated 
having appointments scheduled in advance and minimal waiting, and they contrasted this with traditional care:

You have more time to ask questions. If you forget, you are there for two hours, so you have time to think of what you want to ask, and what you might be going through. I didn't have to wait to get care at all. I just came and just got seen, so that was good. Because after the group ended, before I had my baby, I had to go back to the regular doctor and not the group.... I had to wait! I hated that. 'Cause I had to wait, and then they would see me for like, I don't know, like fifteen minutes or ten minutes. And they don't tell you nothing, really. It was like, "The baby is good. Everything is all right. See you later."

\section{Collaborative Venture: "Everybody Talked to Everybody"}

Being a collaborative venture was the essential mechanism underlying GPNC. GPNC was a dynamic, interactive process and entailed a shift away from traditional patient-clinician roles and relationships. The collaborative venture was based on facilitated group discussion and had two subthemes: facilitative leadership and active participation. Women credited their group leaders with helping participants "open up," and to interact with one another. When asked to describe what group leaders had done to accomplish this, women answered that they had posed questions to the group regarding their experiences and concerns. They particularly liked activities in which group participants each responded to a question in turn. Leaders were also perceived as successful in balancing the needs of individual women and the group during discussions. This created a sense of inclusiveness, which was described by one participant: "She kind of makes everybody put their input together. So as far as asking us each individually how we feel and asking us each the same questions, it kind of makes us feel more related." Women also felt that group leaders had given participants "time to speak" and had encouraged women to serve as models; for example, to demonstrate the sidelying position for breastfeeding. However, when group leaders accepted silence and nonparticipation from the women in their groups, this was also important to some women: "I felt that it was okay to not talk. Like, it was okay to not talk, so that is why I do talk sometimes, because there was no pressure. I was like, okay, you can be yourself." Finally, when group leaders shared personal experiences with the group it helped women to feel comfortable:

She uses her own experiences into relating with us. She'll tell us about her child, and her experience at birth, or even how she had her child there when she delivered one of her babies. So that's one of the ways I feel comfortable, because she can open herself and her own life and experience to us.

Facilitated group discussions were often described by women as "talks" or "conversations." Women enjoyed hearing other peoples' stories and perspectives as well as actively participating in different ways. One woman described her own involvement: "I just enjoyed like group discussions. I always participated. If she needed like a dummy, or somebody to participate I always raised my hand." Women also appreciated when other women contributed. Two women in the same group commented on each other's participation.

[Woman 2] participated a lot, she talked a lot. I admire that, because a lot of people, when they get in groups and stuff, they don't want to talk; they shy away and stuff like that. But she was very open.

I felt that when [Woman 1] herself explained and elaborated to me, to make me understand more about what she was going through, that was very supportive also.

One woman summarized the way in which women's participation served as a springboard for further engagement: 
You gotta raise your hand and ask, or just throw it out there. I'm pretty sure somebody else has the same questions, or probably don't want to say it. But once you say it, everybody else is going to start responding off of it. That's how it usually goes.

This process could also operate in reverse: one woman remarked that lack of participation by others inhibited her own participation.

One feature of GPNC - the circular arrangement of chairs for group discussion—signaled the expectation of less traditional interpersonal dynamics than individual care in an exam room, and might have encouraged participation. Although women never explicitly commented on this arrangement, they captured the experience of being together in the circle implicitly in their use of the term sitting. As reported earlier, this term was used by women to suggest investment. In the following quotation it also connotes a platform for collaboration and participation:

I like the fact that we could all sit here and go back and forth on the issues that we're having during our pregnancy, and what likes we had and what things that we didn't have, and being there with women that were farther along or not so long in their pregnancy. We just like to know, like, this could happen to you because I'm farther along in my pregnancy than you are.

\section{A Social Gathering: "You're Talking and You're Laughing"}

Women portrayed the groups as enjoyable social gatherings rather than medical visits. They described GPNC as fun, looked forward to the next session, and contrasted GPNC with individual visits: "In the beginning it was a little long, but the time goes by fast. Because, you know, you're talking and you're laughing and all that stuff." Several components of GPNC contributed to a relaxed, pleasant atmosphere, including the homelike setting. As women entered the group space, they encountered the circular arrangement of chairs and cheerful wall decorations. Medical equipment was located peripherally and, in one site, chairs were situated on a colorful rug with pillows strewn about. Food and music were sometimes present, and one woman observed that food helped to reduce social awkwardness. Together these features contributed to the sense of attending a social event.

A variety of different activities made GPNC interesting and fun. Women enjoyed when group leaders used varied materials such as a doll and model pelvis, videos, books, posters, and self-assessment sheets from the CenteringPregnancy handbook. Participation and humor also contributed to a social atmosphere. In one setting, a sense of pleasant commotion-of a variety of people moving around and being engaged simultaneously in different activities within the space-also enhanced the informal atmosphere. One participant described it this way:

This is different. You can just walk in a room, there's already people there and the nurses are coming up to us and getting our blood pressures looked at, bellies measured. They ask us questions about how we feel. It's just everything. The whole process is just faster, it was just fun.

A number of resources in the site referred to above contributed to the inviting atmosphere. Groups were conducted in a large room, exams took place at a distance behind a screen, and there was an open area where children could play. People moved about freely and appeared at ease. A second staff member was usually present to greet people as they arrived, to help them to settle in, to assist women with taking vital signs and laboratory testing, and to answer questions during waits. This freed the CNM to focus on conducting exams and facilitating discussion. 
In contrast, the other setting had a smaller, more utilitarian space and the group leader there had little or no staff support (although this gradually improved). Consequently, the midwife simultaneously greeted women, taught self-care, ordered lab tests, obtained supplies from the clinic, and conducted exams. This site's lack of resources did affect the social atmosphere, particularly during the informal time when women entered and checked in. Women often sat quietly, and some women wished for more activities or for this time to be "better organized." One woman expressed frustration with the lack of chitchat:

I didn't like the morale of the other women. Of course in time it got a little better, but my first few sessions, it just almost seemed like nobody wanted to be therelike they weren't happy to be there.

Although this woman primarily ascribed the awkwardness to the reticence of other women, she also noted the impact of the setting on interaction: "But it was just kind of like a small room and nobody wanted to really say anything."

\section{Relationships With Boundaries: "We Had a Little Moment"}

A fundamental aspect of receiving care in a group was forming relationships with the group leader and other participants. These relationships helped women to feel comfortable and invested in groups, enhanced learning, increased participation, and reassured women about pregnancy-related changes and fears. Although a critical component of GPNC, these relationships were also bounded in important ways.

Relationships with the group leader-Most relationships between women and their group leaders had begun early in pregnancy. These connections helped recruit women into the groups and remained central to their feelings about GPNC. Group leaders were seen as decent, caring people whom the women trusted deeply. They were considered open minded and nonjudgmental—someone women could ask about "anything." Women also portrayed them as engaging, almost charismatic, using words such as "energetic," "bubbly," "funny," and "cool":

I really like her. She's just so nice and stuff, and like I was just looking forward to just going and seeing her, because she's just polite and she's just-I don't know.

She always puts a smile on my face.

Although women clearly respected and admired group leaders, certain characteristics, such as being "down to earth" or laughing made them seem "real," and put women at ease. Several women ascribed the success of GPNC to group leaders' attractive personalities. Women also felt that group leaders extended themselves above and beyond the usual norms of care to help them navigate through complex, even daunting health systems. One woman described this as being "catering and loving," and several women told stories illustrating the lengths to which group leaders had gone to facilitate access to or financing of care, follow up on problems, or to remind them of appointments.

Relationships with group leaders were repeatedly described in very positive terms. Women "loved" their group leader, felt they had "clicked," and said that being in the group allowed them to "build more of a friendship" with the midwife. Although in early interviews several women had wished for more time alone with the midwife, in later interviews it was clear that many women had come to feel listened to and cared for as individuals. As one participant said, "With [midwife] it just felt like a one-on-one thing, even though we was in a group, but she took time out for everybody and just made us feel, just good."

Relationships with women and significant others in the group-Women also expressed predominantly positive feelings about the relationships among pregnant women in 
the group, although these relationships had limitations. They almost universally said that group participants got along well, were comfortable interacting, and that there were "no bad vibes." Although some women had known each other prior to joining groups, this was not typical, and many women felt nervous initially. One woman compared this to the anxiety experienced when starting a new school or a job. But these feelings changed over time; as others participated in the group, many women became more comfortable and trusting, and eventually they felt more willing to participate themselves. This tentativeness was described by one participant: "At first you was kind of quiet and not reassured if this is what you wanted to do, and then it was, 'Okay, this is something I'll go for." Women sometimes described the process of getting to know each other as making "friends"; however, this experience was not universal, and women who attended fewer sessions typically had fewer positive comments about their relationships with others in groups.

Concern about the welfare of other women in the group was often evident. One woman refrained from discussing disturbing topics partly because she worried that it might "depress" other pregnant women. Another woman brought several new outfits of baby clothes she had purchased for a woman who had extremely difficult personal circumstances. A few women with partners were particularly careful not to assume that all pregnant women were involved with their baby's fathers. Finally, women were very supportive of other women's partners attending the group, even when their own partner did not. One woman who was experiencing serious difficulties in her relationship with her baby's father commented, "I thought that it was very sweet of him to come with her all of the time. It made me feel happy for them. Somebody cared."

Some newly established relationships between group members continued after groups ended. A few women had exchanged phone numbers and planned to stay in touch, but neither group leader had been able to schedule group reunions, so there was no systematic exchange of contact information. Typically, ongoing relationships took the form of passing encounters in clinic, during hospitalization for birth, or in their neighborhoods. When this happened — as it frequently did-women reported having chatted for a while about their births or their babies. Sometimes group leaders wished that stronger connections and networks had been forged between group members, but one group leader remarked that, although bounded, these relationships nevertheless had significance:

It may not be how I would continue relationships with people that I was in a group with, but maybe it will be, "How is your baby?" when they see each other in the clinic. Or maybe they'll reach out and touch their belly again if they see each other pregnant one more time, or, you know, they'll ask each other about their birth. Hopefully, we'll have already done that, but maybe they'll ask in a real way, "How are you doin' as a mom?" and they'll know that that's okay territory with each other. I'd like to think that.

Despite the apparently casual nature of encounters outside of the groups, women occasionally hinted at a connection that transcended the mere exchange of greetings: "It was like, a little, we had a little moment. 'Cause I guess because we knew each other from the group."

Women often commented on both similarities and differences among the women in their groups. Similarities were comforting, validated women's concerns, and helped them to feel connected with one another. One woman described this feeling: "We were all going through something in common, so it is easy to become comfortable with somebody that you have a lot-well, maybe not a lot in common with, but something very big in common." Women also appreciated differences among the women in groups, but they sometimes found it difficult to articulate why this was important to them: 
Well, everybody had their own things. I think that everybody was just different. Everybody grew differently. Some people had big stomachs, and some people had little stomachs. Some people had different kind of-you know, I can't really explain it. Everybody was just different.

Gaining exposure to different pregnancy experiences and advice derived from diverse perspectives was valued. Differences also provided an opportunity for women to help and mentor each other. Older women liked to share stories with younger women, multiparas advised primiparas, and women later in gestation informed women earlier in gestation about what was ahead. Most women felt extremely supported by the presence of their own partners and family members in the group. Being in the group helped their significant others understand more about the pregnancy experience and enhanced their relationships:

Because when I was pregnant I was at home and acting up and stuff like that. They would come to the group with me. Then they'll understand like why I was acting up. 'Cause then they would be like, "Oh, this is what happen," and your hormones and stuff like that. They would be like, "Oh, you wasn't being, you know, you were just acting up because of your hormones." I was like, "Okay." I felt like they understand me more. They started treating me different, not like this big angry person, but as a pregnant person.

Women were also generally quite supportive of other women's partners attending; however, one woman was critical of the insensitivity she felt some men displayed when they dominated group discussions, or when they talked disrespectfully of their partners in the groups: "A lot of them speak more than others, and it's like it's not about you, it's about the female and her pregnancy and the difficulty she's going through." Children were also readily accepted. Women understood the challenges of finding child care, and tolerated the distractions other women's children created; however, sometimes women found having their own children in the group difficult, and wished the clinic had provided child care during group time.

Boundaries-Although relationships were forged between group members, they had constraints. There were boundaries in two arenas: discussion of sensitive topics and physical privacy. Sensitive topics included bodily functions and profound personal problems such as domestic violence, substance abuse, or homelessness. Some women initially felt awkward discussing "embarrassing" topics such as vaginal discharge, urinary frequency, or sexuality, particularly around men; however, many women noted that they became more comfortable discussing these physiologic issues over time:

Like the vaginal discharge. It's kind of natural, because your cervix is getting more pressure, I believe, and you just, muscles down there and stuff. You mention it because you're going through it and you want to know that you're not the only one going through it.

In contrast, spending time together did not lead women to disclose domestic violence, substance abuse, serious financial problems, or homelessness. Women were reluctant to discuss these topics within their groups for several reasons. First, many had established coping mechanisms which included a sense of privacy and/or dignity. One woman said, "I'm not trying to have a pity party, like, I don't want people to feel sorry for me." Second, women were wary of discussing confidential information with strangers, fearing that it might be discussed outside of the group:

Because I don't know if these girls are going to keep my business confidential. You don't tell all your business the first time you meet someone. You wait, you observe, you take note; you see if you can trust these people. 
Despite reluctance to disclose sensitive issues, some women experiencing profound problems overcame major hurdles to attend consistently. For these women, feeling supported was not contingent on discussing all their concerns with group members, and being in a group with other women filled important needs.

The other set of boundaries related to physical privacy. This included examinations in the group and touching other women during group activities. There was a spectrum of comfort about having physical examinations in the group setting. Some women were perfectly comfortable with examinations in the group:

It's not like anybody's invading my privacy, like I've got to take my clothes off or something. It's just getting the blood pressure, getting my weight, and measuring my belly. I mean that serious, you know what I'm saying? Like oh, somebody's invading my privacy or something like that. You don't really need to be in a closed-up room to do that.

Some women were less comfortable with exams in group. Sometimes this related to the presence of men, including concerns that other women's partners might see them in varying degrees of undress:

I was on the floor listening, getting my belly listened to. My pants are open, of course, and then some guy walks in. And it just threw me off. I felt uncomfortable. Because my pants were open and my belly was exposed.

Many women wanted a visual barrier and greater sound privacy for discussions of personal issues. Even when a screen was present, some women still felt a lack of privacy; one woman positioned her partner to block the small opening to the examination area.

Women also had varying reactions to being asked to serve as a model in the group. One woman volunteered eagerly to help demonstrate how midwives assess fetal position abdominally, but another woman declined, saying, "I'm a very private person." A third woman was "reluctant," but eventually agreed: "I wanted to contribute to the group, so I finally gave in. Everybody touched my stomach, and I was all right with it." Another woman suggested that comfort with physical intimacy might increase over time as relationships developed between women: "Maybe in the beginning she wouldn't have laid there. So now she trusted us to feel her stomach and stuff like that."

\section{Learning in the Group: Learning so You Understand}

The greatest amount of coded text related to learning, and comments about learning were almost universally positive. Woman noted that learning was promoted primarily by group leaders and the group discussion format, although several additional features also contributed to learning. Group leaders were seen as engaged, resourceful educators. They did not merely provide information; they went out of their way to assure that every participant in group understood what was being discussed. Women identified a range of strategies - both verbal and nonverbal - employed by group leaders to insure understanding. Verbal strategies included explaining, elaborating, offering information so that women did not have to ask, asking questions to the group and answering people's questions, giving examples, and reviewing information. Several women also said the group leader fostered learning by listening. One woman described this process, saying, "The midwife listens and the questions that I ask her, she has the right answers for."

Group leaders augmented verbal strategies with assorted approaches and materials that addressed different learning styles. They demonstrated mechanisms of labor using models, fashioned a cervix out of modeling clay to help participants visualize dilatation and effacement, and had group participants-including significant others-try exercises to 
relieve discomforts. Group leaders also asked women to serve as models for demonstrations of breastfeeding positions or labor support techniques. There was widespread appreciation of these nonverbal strategies. One participant explained, "She does a lot of examples and she uses us to show the other girls what she's really talking about, like more hands on. I like it."

Women also learned from videos, posters, and written materials from the CenteringPregnancy handbook. Some women liked having homework and reported having read the handbook or having used relaxation CDs provided by the group leader. However, the resources needed for conducting these varied activities were not always available to the group leaders. In addition, women felt that lively, engaging group leader personalities made learning fun and enhanced understanding. For example, several women described group leaders as not being the "boring type that reads you the book." They contrasted group leaders' "animated and real" styles with previous learning experiences: "CCause I went to school before but I didn't like, really pay attention to the drawings that she showed us. But I really got to the point where I understand it now." Finally, group leaders were seen as credible sources with both professional expertise and life experiences: "She's a midwife, and what is there that she'd not know about pregnancy? 'Cause that is what she studied and she's been through it before."

Women also identified several aspects of the interactive discussion format as central to their learning. This included being able to ask questions, hearing other women's concerns and questions, learning from others' experiences, and having the opportunity to tell stories. Tying these individual components together was the collaborative nature of the venture. Women felt free to ask questions and interact. Being engaged helped them to understand more fully the information provided in explanations or demonstrations. Listening to other women's interactions with group leaders also provided answers to questions that women had not thought of themselves, or that they had forgotten to ask (although one woman said she would have asked more questions in individual care). One woman who did not want to ask questions herself described how she learned from listening to others:

But I didn't want to like say anything. Somebody else would come up, and they would say something, then [group leader] would answer. Then I was like, okay. [Group leader] would ask a question, and I don't answer, but I know what she is talking about. Somebody else would answer. It was just great.

Women were also eager to hear other people's experiences and opinions, and these differences among women contributed to their learning: "Maybe somebody has a different way of dealing with something, and they might be able to tell you, other than the doctor."

Several additional features of GPNC also promoted learning. Women were pleased with the amount and range of topics covered in discussions. Some multiparas compared this favorably with information received in previous pregnancies. Women particularly valued learning about pregnancy discomforts and relief measures, nutrition, avoiding harmful chemicals, what to expect in labor, labor pain management, and parenting strategies. Several women noted that GPNC helps women "know more about pregnancy," and distinguished this from childbirth classes, which focus on labor and birth. Self-care also contributed to learning. A few women indicated that taking their own blood pressure, weighing themselves, and keeping their own records in CenteringPregnancy notebooks had helped them to understand and become more proactive about managing their own health:

I was more on track of my progress. When you go to another appointment, you don't remember what you weighed last or what the baby's heartbeat was. But in our binders that I did read, even though I knew most of it, I did read it all and it was just great having the extra information and to be able to come in and do my own blood pressure, and my own weight and, you know, then be seen. Or like when I 
was losing weight, we seen that I was this now, and then I've lost this. You know, what are we going to do about it? Well, what's the problem?

In one setting, women were not always taught to take their blood pressure. When this occurred, women reported that they felt insecure with their knowledge and skills, and did not want to provide self-care: "I'd rather someone else do it for me than for me to do it, because I don't understand. I especially don't understand the blood pressure."

Several women indicated that the extended period of time they spent in the group enhanced learning:

I just feel that I learn more than just going to a doctor's visit. You have more time to ask questions. If you forget, you are there for two hours, so you have time to think of what you want to ask, and what you might be going through. And find out the information before you leave instead of waiting for your next appointment.

\section{Changing Self: "It Was Not Just Me, and the World's Not Over"}

Women had many fears and anxieties related to pregnancy. Receiving care in a group, however, modified their pregnancy attitudes. It also led to improved health behaviors and a greater sense of responsibility for self-management of health.

Changes in pregnancy attitude-Pregnancy, although exciting, was often perceived as stressful or frightening. Unsurprisingly, women were very concerned about their health and their baby's welfare. These concerns were often exacerbated, however, by feeling uninformed and confused about physical and emotional changes in pregnancy. Women also worried about who would support them in labor, and they had many fears about birth, such as adverse medication reactions, labor pain, cesarean birth, epidurals, and dying.

In addition to health concerns, many women entered the groups with complicated personal situations that profoundly affected their pregnancy attitudes. Some women had limited or no support from their baby's father. Many had tenuous financial situations or had lost their jobs. Several women experienced domestic violence, infidelity, or became homeless during pregnancy. These women faced considerable uncertainty about their living situations, providing for their new babies, and keeping their children safe:

Yeah, I'm not even gonna lie. In the beginning I thought, "Okay, I'm pregnant. This is a piece of a cake." Now it's like, "Oh! I'm pregnant." My relationship with my grandmother is ruined. My relationship with my baby's father's mother is ruined. Does all this come with being pregnant?

For other women, pregnancy was a predominantly happy time. Nevertheless, even these women hinted at pregnancy as being a precarious state, a "predicament" in which relationships with families and partners became particularly vulnerable: "Everybody's very supportive, so I'm thankful for that. 'Cause, most women they go through like different situations to where they get kicked out of their homes because of the pregnancy. But mine's totally different. Everybody is accepting."

One of the most prevalent attitudes related to pregnancy was feeling unique in having certain feelings, fears, or personal problems. These sentiments were communicated repeatedly by a majority of women from all age, race, and parity groups. However, GPNC changed this; being in the group helped many women to feel both more comfortable and more comforted. This derived in part from normalization. Learning about pregnancy helped women understand normal physiological and psychological changes, which then helped them feel more relaxed and less scared. Beyond acquiring information and understanding about these changes, being with other women in groups also helped women to feel less 
unique in their concerns and to feel that they were "not crazy." They also learned that other women experienced difficult personal circumstances surrounding their pregnancies. This normalized their own social and economic situations, and helped women to feel less isolated and less fearful:

It made me feel like, more relaxed. It was not just me, and the world's not over, and stuff like that.

Their stories helped me out with some of the things I was going through. It felt like I knew someone else was feeling like it. So, it didn't scare me as much. Like, you know how you have the shortness of breath? I just really felt like I was the only one going through that. And then when we talked in group, like, all the other ladies was talking about it. So I was like, you know, it's not just me, and it just was a lot of things like that.

When women understood that they had concerns and anxieties in common, they also wanted to reassure others:

So it was just like, it's [birth], done and over with. I got to share my experience with her [other participant], like how it was, you know, don't be scared, you know, look for this and stuff like that.

Feeling comforted by GPNC, although a highly prevalent finding, was not universal. Infrequently, anxieties were heightened rather than decreased. For example, women sometimes raised concerns or shared frightening stories:

One of the ladies was tellin' us how she had to be rushed to the emergency room 'cause she was bleedin' real bad and stuff. And I was like, "Wow!' 'Cause I never really heard anybody talk about that before. It was just like a scary feeling, like you could actually go through that.

One group leader suggested that, although ostensibly upsetting, these discussions in fact were often beneficial, because pregnant women regularly encounter "old wives' tales" or "war stories" outside of the group-without the resources to process them. But being in the group provided women the opportunity to process their stories with professionals who could provide correct, relevant information.

Finally, many women expressed dismay when they discovered that, owing to rotating call schedules, their group leaders would not necessarily attend their births. One midwife said she felt that the women's need for her to be at their respective birth indicated that she had not succeeded in fostering their sense of independence and self-assurance, an outcome she hoped GPNC could help women achieve.

Changes in self-management of health-Women attributed changes in specific health attitudes or behaviors, as well as an increased sense of control, to receiving prenatal care in the group. They felt they understood more about pregnancy, signs of labor, strategies for relaxation, and dealing with labor pain. Consequently, they felt more confident about facing labor and birth. More than half of the women interviewed (and everyone interviewed postpartally) traced one or more health behavior changes to GPNC. For example, one woman attributed deciding to have a vaginal birth rather than a repeat cesarean to GPNC, and two women identified group discussion as having convinced them to "go natural" and to decline an epidural. Three women mentioned deciding to breastfeed based on information received in the group. One of these women credited being in the group with developing her resolve to persist despite pressures to stop:

I just told them this is what I wanted to do. I mean, breast is better than formula, and it's just something that I wanted to do. Like I said it through my whole 
pregnancy, "I'm going to breastfeed, I'm going to breastfeed." Even if it's just for a month or two, I was going to breastfeed.

Several women said that they had implemented strategies learned in the group to help siblings adjust to a new baby. Three women reported improved eating habits resulting from nutrition discussions. One woman with chronic hypertension planned to use her new understanding of nutrition to improve her blood pressure, with the goal of discontinuing medication.

Being in a group helped several women to plan ahead or gain new control over some aspect of their lives. This included setting and writing down personal goals; planning return to work, child care, and/or contraception; gaining confidence about parenting; and using new strategies for anger management at home:

It helped because they asked us about are we going to go back to work and what were our plans going to be. So it kind of made you kind of plan ahead. Also they asked us if we wanted to do the birth control or if we're just not going to get any, so it also helped because I got the IUD. So it made me think whether I wanted to do the IUD or the shot.

Another woman learned from group discussion that she could choose a pediatrician, and relished assuming this new responsibility:

I really didn't know how to go about it, because I thought you had to stay with the doctor they give you. It was reassuring that I don't have to do that if he's not the right one or she's not the right one. And it's between me and my partner to figure out the baby's care, it's not just up to me. Now that I have a little bit more of an idea of what we can do, when the baby is here I'm going to sit and talk to my partner and see what we both decide on.

A few women expressed pride in their new behaviors, knowledge, and sense of control. One woman explained: "'Cause not having an epidural was really a lot. I am feeling everything, and I hadn't had any of my kids without the epidural before. I thought that I could never even have a baby without any medicine." Women also felt they had chosen well in electing to receive care in a group, and that they would make the same choice again. Some partners were also impressed with what the women had learned:

He likes that I' $m$ in the group because before he was like, "Oh, you don't know nothing about no baby." So now, like whenever I go to group, I can come home and be like, "Well, I learned this today, and that today." So he goes, "Oh, you know a lot."

Finally, one woman talked about her career plans, which had been derailed by unexpected life events. She described being inspired by her group leader's caring and support of women in the group to find a way to help others. She reflected on her goals and the importance of this kind of work:

When I was growing up, I wanted to be a teacher, because I wanted to help kids learn. And then I changed my mind and I wanted to be a lawyer. Now that I'm having a child, I definitely want to open up a business that would benefit everybody. And what she's doing is great, because she prepared me and she helped me so much. I just feel grateful only because there's probably a lot of women out there that couldn't get this help, and is very naïve about the pregnancy. And who knows? Maybe not getting enough support causes young girls to put their fetuses in trash bags and throw them out. It's just ridiculous, you know? So I'm thankful. 


\section{Discussion}

Group prenatal care offered women a positive overall experience and was found to meet many of women's expressed preferences regarding prenatal care (Novick, 2009). In this research, we identified six themes, each of which represented a major aspect of women's experience of GPNC. These aspects also worked in concert to build the overall experience. Moreover, when individual aspects of the experiences of GPNC were weak or absent, other components were attenuated. Added to this dynamic interplay of component elements was the passage of time: as women spent time together, they experienced changes of pregnancy together, developed stronger relationships, became more willing to share experiences and advice, and became increasingly comfortable being in the group together.

Although this research yielded a large number of findings, some were particularly robust in that they were highly prevalent in the comments of participants; occurred across individuals, groups, or sites; or resonated strongly with or illuminated other ideas, themes, or researcher observations. These particularly strong themes, reflecting both positive and negative aspects of women's experiences, merit additional discussion.

Some aspects of the experiences of GPNC were consistently positive. Women consistently had highly favorable reactions to the strong educational component of GPNC. This is unsurprising in view of previously reported findings regarding women's expressed needs for pregnancy-related health information (Novick, 2009). But beyond the mere receipt of information, women felt GPNC helped them to "understand"-and they contrasted this sharply with previous educational and health care experiences. In groups, women gained understanding from talking with other women: they asked one another questions, told stories, and offered and listened to advice. However, women principally attributed their ability to understand to the resourcefulness and persistence of group leaders, whom they perceived as truly invested in their learning.

In general, the women portrayed group leaders as deeply caring, and the women reciprocated with their affection, admiration, and trust. Researchers in previous studies have reported on the importance women place on their relationships with prenatal care staff and providers (De Koninck, Blais, Joubert, Gagnon, \& L'Equipe d'evaluation des projets-pilotes, 2001; Malchodi et al., 2002; Milligan et al., 2002; Sword, 2003). Several authors also described the feelings of some women that they had been treated harshly, rudely, or dismissively during prenatal care (Kennedy et al., 2009; Sheppard, Zambrana, \& O'Malley, 2004; Sword). Because unpleasant experiences of care might occur more frequently among low-income and minority women (Milligan et al., 2002; Sheppard et al.; Sword), GPNC might provide a unique opportunity to nurture strong, positive relationships between women from vulnerable populations and their clinicians. Group leaders' nonjudgmental attitudes and willingness to share their own feelings and experiences also helped women to feel comfortable participating in a group, and might have modeled empathy and self-disclosure (Yalom, 1995). These relationships between women and group leaders created a foundation for women's relationships with one another.

The women enjoyed being with others who were both similar to and different from themselves. When combined, these two sets of effects might have operated synergistically. Differences might have prompted women to think in novel ways, thus generating learning and change. But similarities might have enabled the women to become more comfortable and connected with one another, leading to increased participation and greater sharing across differences.

Every woman who was interviewed postpartally reported at least one health behavior change, or having a greater sense of being empowered, as a consequence of GPNC. 
Although the number of changes reported was not large, women's comments suggest that they might be significant as initial steps toward becoming more proactive managers of their own health and/or consumers of health care services. These steps toward greater empowerment might be particularly meaningful for low-income, minority women.

Finally, one of the strongest positive findings of this research was that sharing the experience of pregnancy with others provided powerful reassurance through the normalization of pregnancy changes and concerns. Many women found pregnancy to be a stressful, frightening time, yet they were also excited to be pregnant. Many women initially were unaware that others were experiencing similar physiologic changes, fears, or even paradoxical emotions about pregnancy. On one level, normalization resulted from simply learning about pregnancy changes and strategies for adapting. Beyond this, however, hearing stories from other women that resonated with their own experiences helped women to feel profoundly comforted: they discovered that they were "not the only one" having certain problems and that they were not "crazy." These findings are highly consistent with Kennedy's findings that women were "delighted and often surprised" (Kennedy et al., 2009) to discover that they were not alone in their experiences. Yalom (1995) noted that an important benefit of being in groups is the realization that, despite their differences, participants are not unique in their experiences and worries. Participants in this study reported that sharing the experience with others provided companionship, decreased loneliness and stress, and helped some women to realize that they could face the unknown.

It is important to recognize that there were some aspects of the experience of GPNC that women portrayed more negatively. Women were not enthusiastic about receiving physical examinations in the group. Although the majority of women did not explicitly object to this feature of care, no one volunteered positive comments, and several women expressed negative feelings. These included feeling unprepared for the way in which examinations were conducted and being "exposed" during examinations. Furthermore, some women were not certain that their physical care was adequate. Although they did not specify omissions in their care, some women thought they might not be receiving the "full exam." This suggests that some women, rather than feeling comforted or empowered by the informality of examinations in the group, worried that they were receiving second-rate care. This could be a particularly important consideration when providing care to low-income and minority women.

As noted earlier, women in Kennedy's study of GPNC (Kennedy et al., 2009) also felt rushed during exams, and wished for greater privacy and more personal time with providers. Therefore, negative reactions to having examinations in the group might cut across populations and settings. Because integrating physical care with education and support is so central to this approach, differentiating GPNC from both conventional prenatal care and childbirth education classes, it is critical to fully understand and address these privacy needs. It is also important, however, not to overemphasize these negative reactions. Although these were consistent findings that point to ways in which the GPNC model could be modified to improve experience, they did not appear to seriously undermine women's overall experiences.

The other important negative finding was the bounded nature of the relationships between women. Women did not proactively maintain connections after groups ended, nor did they disclose sensitive topics such as domestic violence, homelessness, partner infidelity, job loss, or family stresses. One woman wished that conversations would touch on these issues:

I wanna know if the other girls are going through what I'm going through. Is everything okay with them? Like it's not okay with me? There's some of the things that I wanna talk about in a group. Because... okay, yeah, you gotta eat healthy; 
you gotta watch your weight. But I wanna talk about things like this: Is it really that bad?

Other women clearly did not want to share these kinds of problems with the group. They had pride in maintaining privacy and in refraining from burdening other women. They gained support from groups without discussing every issue. Time spent with others in groups might even have served as a retreat from these problems.

One question raised by these findings is: Why did GPNC, which holds out the promise of social support, not lead to deeper, more lasting relationships among women? There are several possible explanations. Many women who participated in this study experienced poverty, job loss, homelessness, domestic violence, and/or family crises during their pregnancies. Most of the women were about to become-or already were-single mothers. These profound stressors might have contributed to irregular attendance, thereby decreasing group stability. In addition, because women often lacked babysitters, children were often present during sessions. This might have deterred disclosure of sensitive information. Furthermore, clinics did not always provide appointment reminders, conduct reunion sessions, or continue groups when attendance dwindled toward the end of a series as women of varied gestational ages gave birth. There is evidence that groups with short duration, high turnover, or irregular attendance are less stable and cohesive, and therefore less therapeutic (Yalom, 1995). In addition, when supplies and support staff were lacking, social atmosphere and interaction between the women were compromised. If these elements of the infrastructure supporting groups had been consistently present, stronger relationships among women might have developed.

Finally, it is possible that a single program that lasts 8 months cannot, in isolation, produce major life changes. For the greater promise of GPNC to be realized, in terms of social support as well as self-management of health, GPNC might have to be situated within a network of similar programs that reinforce each other's efforts to promote supportive relationships within the community, and to empower women to assume more control of their own health.

\section{Clinical Implications}

A number of clinical implications can be drawn from women's reactions and suggestions. First, recruitment should be considered a crucial first step in providing GPNC, because adequate pregroup preparation can reduce dropout rates, improve participation, and decrease anxiety (Yalom, 1995). Procedures for recruiting women into groups could include interactive discussion, written handouts, and photos and/or videos of group sessions to help women visualize this unfamiliar approach. More specifically, certain features of GPNC should be explained carefully in advance; foremost is providing the rationale for and description of physical examinations in the group.

Once groups have begun, it might help to reinforce that all the components of care are being provided and to elicit women's questions about GPNC. When relevant, women also need to be informed that men might be present, and that their clinician group leader might not be their birth attendant. Recruitment by a clinician whom women know and trust might reduce uncertainty and enhance group stability (Hackley et al., 2009).

Second, several features of GPNC that might seem frivolous or "extra" might truly be important to women's experiences. Having comfortable chairs, food, and pleasant décor might promote a sense of attending a friendly social gathering. The dimensions of the group space should also be adequate to permit pregnant women to move around comfortably, and an area rug should be provided for floor exercises. Examinations should be conducted 
behind a screen at a distance from the group that allows visual and sound privacy. Music might also enhance sound privacy. In addition, the full 1.5 to 2 hours should be scheduled for sessions, as this extended time contributes to an unhurried atmosphere and promotes investment in groups. Postpartum reunions should be held: Many women wanted to share their birth stories and exchange contact information, and reunions might promote ongoing connections. Resources should also be provided to enable group leaders to employ a wide range of strategies to meet varied learning styles. This includes having equipment such as TVs, videotapes/DVDs, three-dimensional models, posters, CDs, and books available in the group space. This would enable group leaders to respond to questions and topics as they arise and to keep group members actively engaged in learning. Although clinical settings might struggle to fund these components of GPNC, economizing is not without its own cost; it might ultimately compromise the relaxed, pleasant atmosphere that promotes interaction and development of relationships among women.

Third, adequate staff support is essential. Group leaders need to provide physical examinations without distraction. In addition, group facilitation requires the full attention of at least one clinician who is not simultaneously attending to laboratory tests, late arrivals or other interruptions. Ideally, child care should also be provided as children can be disruptive - particularly for their own mothers - and women might refrain from discussing certain topics in their presence.

Fourth, women with a wide range of gestational ages are sometimes included in one group to increase membership. This might occur at sites with low prenatal care volume, or at sites that do not recruit adequate numbers of women into GPNC. Women in this study accepted and even appreciated heterogeneous groupings; however, having varied gestational ages in a group resulted in some women joining the group late, and others leaving early because of birth. This shifting membership might undermine group stability and cohesiveness. Therefore, although some settings might require inclusion of varied gestational ages in individual groups to sustain GPNC, this approach has distinct disadvantages.

\section{Limitations}

The principal limitation of this study is the possibility that women's experiences of GPNC might be less positive than the findings reported here suggest. There are several ways this might have occurred. First, the experiences of two sets of women who might have had more negative experiences of care were not fully captured in this data: the women who were lost to follow-up after discontinuing GPNC and the women who remained in GPNC but did not have all three interviews.

Second, it is possible that, as a nurse-midwife, the first author could have been viewed by group members as part of the "authority structure" of the group. This perception, if present, might have reduced study participants' willingness to share negative perceptions of the group process, group leaders, or health care setting (D. Berg, personal communication, July $16,2006)$. In addition, the first author's background and previous experience with different models of prenatal care might have introduced bias in her interpretation of the women's experiences; however, frequent journaling and field supervision were conducted during data collection to identify, understand, and minimize this potential bias. Furthermore, because a fairly positive picture of women's experiences began to emerge during data analysis, disconfirming cases and counterexamples to each theme were actively explored.

Because the GPNC groups studied were all conducted in English, the findings reported here do not reflect the experiences of non-English-speaking Hispanic women. Furthermore, all the women in this study were from low-income and minority groups, and might have had limited health care choices. When options are limited, people sometimes develop "adaptive 
preferences," leading them to accept what is available (Nussbaum, 1997). This has been suggested previously as one explanation for a widespread lack of recognition of women's dissatisfaction with standard, individual care (Novick, 2009). In this study, however, adaptive preferences could have resulted in a high level of acceptance of GPNC. The short duration of several interviews and the brief or occasionally puzzled responses to questions about preferences and reactions to care did suggest that some women might be unaccustomed to critiquing health care services. However, despite their limited options, several women who participated in this study had clear and articulate reactions. They compared GPNC with individual prenatal care received in previous pregnancies or at other points in the current pregnancy, or with other health care services they had received.

Additional limitations relate to possible effects of researcher involvement on women's experiences of GPNC. The presence of a researcher in groups might have influenced group members' behaviors; however, repeated contact might have reduced the sense that the first author was a stranger, and thus reduced participant reactivity to her presence. In addition, the interview process might have altered women's experiences of GPNC. It is hoped that the benefits of prolonged researcher involvement, including the collection of rich data across multiple sources and acquiring group members' trust, outweighed these potential disadvantages.

Finally, as this was a naturalistic study, no attempt was made to assure fidelity to the CenteringPregnancy model, or to conduct direct comparisons with traditional, individual prenatal care. However, this naturalistic approach generated an understanding of how GPNC is implemented under nonexperimental circumstances and of the experiences of women who chose to receive GPNC in actual clinical practice.

\section{Implications for Future Research}

It is critical to continue to develop evidence regarding the experience of GPNC from the perspectives of those who receive this care (van den Hoonaard, 2009). Future research into the experience of GPNC should be conducted using multiple data sources such as those used in this study, but should include participants from more diverse social, economic, racial, and geographic populations and health care settings. Such variation might generate different central typologies and/or variants of the experience of GPNC.

Researchers should also investigate in depth the separate components represented by the six themes identified here, to elucidate subthemes more fully, and to determine how individual components of the experiences of GPNC interact to create the overall experience. In addition, because unpleasant experiences of care affect care utilization (Mikhail, 1999; Milligan et al., 2002; Sword, 2003; Tandon, Parillo, \& Keefer, 2005), research should be conducted to examine the relationship of experience to utilization. Research should also be conducted to compare women's experiences of group and individual care and the relationship of experience to pregnancy outcomes. It is also essential to conduct research to develop an understanding of the experiences of women who have discontinued GPNC.

There are aspects of the Centering model of GPNC that are not always put into practice. The challenges clinicians and settings face when providing GPNC need to be explored, as well as the impact of implementing only some elements of Centering on women's experiences of GPNC. This should include comparative case studies and surveys to identify, describe, and understand factors that affect implementing and sustaining this complex model. 


\section{Conclusion}

Group prenatal care provided an opportunity for women to connect with other pregnant women in meaningful ways. Group leaders established a supportive social atmosphere, facilitated group discussions, and helped women learn. Over the course of the group series, women gradually became invested in one another and the group, developed relationships, and shared stories and advice. Ultimately, GPNC helped to reduce social isolation and normalized pregnancy-related fears. The different features of the experiences of GPNC operated in concert over time to create the overall experience. However, when some features were not present, women's experiences were diminished. Therefore, provision of some components of the GPNC model that might seem at first glance like inessential "frills" might, in fact, be important. GPNC has been demonstrated previously to improve important pregnancy outcomes and women's satisfaction with care when compared with standard, individual visits. Based on the research reported here, GPNC also appears to meet many women's expressed needs regarding prenatal care and, for most women, GPNC is an enriching experience.

\section{Acknowledgments}

We thank the women and midwives who generously shared their perceptions of group prenatal care, as well as the administrators and staff in both clinics who facilitated this research. We also thank David Stayner for his advice and expertise regarding interpersonal dynamics and processes in groups.

\section{Funding}

The authors disclosed receipt of the following financial support for the research and/or authorship of this article:

March of Dimes Graduate Nursing Fellowship

Yale University School of Nursing, Department of Health and Human Services Public Health Services, T-32

Training Grant NR008346

Department of Health and Human Services, NIH/ NINR, NRSA Fellowship F31NR009911

Sigma Theta Tau International Research Grant

Evelyn Anderson Research Fund Award

\section{References}

Ayres L, Kavanaugh K, Knafl K. Within-case and across-case approaches to qualitative data analysis. Qualitative Health Research. 2003; 13:871-883. doi:10.1177/1049732303013006008. [PubMed: 12891720]

Baldwin KA. Comparison of selected outcomes of CenteringPregnancy versus traditional prenatal care. Journal of Midwifery \& Women's Health. 2006; 51:266-272. doi:10.1016/j.jmwh. 2005.11.011.

Bernard, H. Research methods in anthropology: Qualitative and quantitative approaches. 3rd ed.. Lanham, MD: Altamira; 2002.

Bloom K. Use of the CenteringPregnancy program in a school-based clinic: A pilot study. Clinical Excellence for Nurse Practitioners. 2005; 9:213-218.

Caelli K, Ray L, Mill J. 'Clear as mud': Toward greater clarity in generic qualitative research. International Journal of Qualitative Methods. 2003; 2(2):1-24. Retrieved from http:// ejournals.library.ualberta.ca/index.php/IJQM/index.

Carlson M, Lowe N. CenteringPregnancy: A new approach in prenatal care. MCN, The American Journal of Maternal/Child Nursing. 2006; 31:218-223. Retrieved from http://journals.lww.com/ monjournal/pages/default.aspx. 
Centering Healthcare Institute. Site approval: Centering Healthcare site approval process. 2009. Retrieved from http://www.centeringhealthcare.org/pages/centering-model/site-approval.php

De Koninck M, Blais R, Joubert P, Gagnon C, L'Equipe d'evaluation des projets-pilotes s-f. Comparing women's assessment of midwifery and medical care in Quebec, Canada. Journal of Midwifery \& Women's Health. 2001; 46:60-67. doi:10.1016/S1526-9523(01)00093-9.

Emden C, Sandelowski M. The good, the bad and the relative, part two: Goodness and the criterion problem in qualitative research. International Journal of Nursing Practice. 1999; 5:2-7. doi:10.1046/ j.1440-172x.1999.00139.x. [PubMed: 10455610]

Grady M, Bloom K. Pregnancy outcomes of adolescents enrolled in a CenteringPregnancy program. Journal of Midwifery \& Women's Health. 2004; 49:412-420. doi:10.1016/j.jmwh.2004.05.009.

Hackley B, Applebaum J, Wilcox W, Arevalo S. Impact of two scheduling systems on early enrollment in a group prenatal care program. Journal of Midwifery \& Women's Health. 2009; 54:168-175. doi:10.1016/j.jmwh.2009.01.007.

Hamilton, B.; Martin, J.; Ventura, S. Births: Preliminary data for 2007. 2009. Retrieved from http://www.cdc.gov/nchs/data/nvsr/nvsr57/nvsr57_12.pdf

Ickovics JR, Kershaw TS, Westdahl C, Magriples U, Massey Z, Reynolds H, Rising SS. Group prenatal care and perinatal outcomes. Obstetrics \& Gynecology. 2007; 110(No. 2, Part 1):330 339. doi:10.1097/AOG.0b013e31816bf6bd. [PubMed: 17666608]

Ickovics JR, Kershaw TS, Westdahl C, Rising SS, Klima C, Reynolds H. Group prenatal care and preterm birth weight: Results from a matched cohort study at public clinics. Obstetrics \& Gynecology. 2003; 102:1061-1067. doi:10.1016/S0029-7844(03)00765-8.

Kearney MH. Focus on research methods. Levels and applications of qualitative research evidence. Research in Nursing \& Health. 2001; 24:145-153. doi:10.1002/nur.1017. [PubMed: 11353462]

Kennedy H, Farrell T, Paden R, Hill S, Jolivet R, Willetts J, Rising SS. "I wasn't alone"-A study of group prenatal care in the military. Journal of Midwifery \& Women's Health. 2009; 54:176-183. doi:10.1016/j.jmwh.2008.11.004.

Kershaw TS, Magriples U, Westdahl C, Rising SS, Ickovics J. Pregnancy as a window of opportunity for HIV prevention: Effects of an HIV intervention delivered within prenatal care. American Journal of Public Health. 2009; 99:2079-2086. doi:10.2105/AJPH.2008.154476. [PubMed: 19762662]

Klima C. Introduction of CenteringPregnancy in a public health clinic. Journal of Midwifery and Women's Health. 2009; 54:27-34. doi:10.1016/j.jmwh.2008.05.008.

Klima CS. Centering Pregnancy: A model for pregnant adolescents. Journal of Midwifery \& Women's Health. 2003; 48:220-225. doi:10.1016/S1526-9523(03)00062-X.

LeCompte M, Goetz J. Problems of reliability and validity in ethnographic research. Review of Educational Research. 1982; 52:31-60. doi:10.3102/00346543052001031.

Lincoln, Y.; Guba, E. Paradigmatic controversies, contradictions, and emerging confluences. In: Denzin, NK.; Lincoln, YS., editors. Handbook of qualitative research. 2nd ed.. Thousand Oaks, CA: Sage; 2000.

Malchodi C, Oncken C, Dornelas E, Caramanica L, Gregonis E, Curry S. The effects of peer counseling on smoking cessation. Obstetrics and Gynecology. 2002; 101:504-510. doi:10.1016/ S0029-7844(02)03070-3. [PubMed: 12636954]

Marshall, C.; Rossman, G. Designing qualitative research. 3rd ed.. Thousand Oaks, CA: Sage; 1999.

Massey Z, Risser P, Ickovicks J. CenteringPregnancy group prenatal care: Promoting relationshipcentered care. J Obstetric, Gynecologic \& Neonatal Nursing. 2006; 35:286-294. doi:10.1111/J. 1552-6909.2006.00040.x.

Mikhail BI. Perceived impediments to prenatal care among low-income women. Western Journal of Nursing Research. 1999; 21:335-350. doi:10.1177/019394599902100305. [PubMed: 11512202]

Miles, MB.; Huberman, AM. Qualitative data analysis: An expanded sourcebook. 2nd ed.. Thousand Oaks, CA: Sage; 1994.

Milligan, R.; Wingrove, BK.; Richards, L.; Rodan, M.; Monroe-Lord, L.; Jackson, V., et al. Perceptions about prenatal care: Views of urban vulnerable groups. BMC Public Health. 2002. Retrieved from http://www.biomedcentral.com/content/pdf/1471-2458-2-25.pdf 
Mooney, SE.; Russell, MA.; Prairie, B.; Savage, C.; Weeks, WB. Group prenatal care: An analysis of cost; Journal of Health Care Finance. 2008. p. 31-41.Retrieved from http://www.aspenpublishers.com/Product.asp?catalog_name=Aspen\&product_id=SS10786767

Novick G. CenteringPregnancy and the current state of prenatal care. Journal of Midwifery \& Women's Health. 2004; 49:405-411. doi:10.1016/j.jmwh.2004.06.001.

Novick G. Is there a bias against telephone interviews in qualitative research? Research in Nursing \& Health. 2008; 31:391-398. doi:10.1002/nur.20259. [PubMed: 18203128]

Novick G. Women's experience of prenatal care: An integrative review. Journal of Midwifery \& Women's Health. 2009; 54:226-237. doi:10.1016/j.jmwh.2009.02.003.

Nussbaum, MC. Cultivating humanity. Cambridge, MA: Harvard University Press; 1997.

Patton, MQ. Qualitative research \& evaluation methods. 3rd ed.. Thousand Oaks, CA: Sage; 2002.

Rising S. Centering Pregnancy: An interdisciplinary model of empowerment. Journal of NurseMidwifery. 1998; 43:46-54. doi:10.1016/S0091-2182(97)00117-1. [PubMed: 9489291]

Rising S. Personal communication. 2009

Rising S, Kennedy HP, Klima C. Redesigning prenatal care through CenteringPregnancy. Journal of Midwifery \& Women's Health. 2004; 49:398-404. doi:10.1016/j.jmwh.2004.04.018.

Robertson B, Aycock DM, Darnell LA. Comparison of Centering Pregnancy to traditional care in Hispanic mothers. Maternal and Child Health Journal. 2009; 13:407-414. doi:10.1007/ s10995-008-0353-1. [PubMed: 18465216]

Rodgers B, Cowles K. The qualitative research audit trail: A complex collection of documentation. Research in Nursing \& Health. 1993; 16:219-226. [PubMed: 8497674]

Sandelowski M. Focus on research methods. Sample size in qualitative research. Research in Nursing \& Health. 1995; 18:179-183. doi:10.1002/nur.4770180211. [PubMed: 7899572]

Sandelowski M. Whatever happened to qualitative description? Research in Nursing \& Health. 2000; 23:334-340. doi:10.1002/1098-240X(200008)23:4<334::AID-NUR9>3.0.CO;2-G. [PubMed: 10940958]

Sandelowski M. What's in a name? Qualitative description revisited. Research in Nursing \& Health. 2010; 33:77-84. doi:10.1002/nur.20362. [PubMed: 20014004]

Schappert, S.; Rechsteiner, E. Ambulatory medical care utilization estimates for 2006. 2008. Retrieved from http://www.cdc.gov/nchs/data/nhsr/nhsr008.pdf

Sheppard VB, Zambrana RE, O'Malley AS. Providing health care to low-income women: A matter of trust. Family Practice. 2004; 21:484-491. doi:10.1093/fampra/cmh503. [PubMed: 15367469]

Stemig C, Stemig C. CenteringPregnancy: Group prenatal care. Creative Nursing. 2008; 14:182-183. doi:10.1891/1078-4535.14.4.182. [PubMed: 19090092]

Stevens J, Iida H, Ingersoll G. Implementing an oral health program in a group prenatal practice. JOGNN. 2007; 36:581-591. doi:10.1111/J.1552-6909.2007.00189.x. [PubMed: 17973702]

Sword W. Prenatal care use among women of low income: A matter of "taking care of self". Qualitative Health Research. 2003; 13:319-332. doi:10.1177/0095399702250128. [PubMed: 12669334]

Tandon SD, Parillo KM, Keefer M. Hispanic women's perceptions of patient-centeredness during prenatal care: A mixed-method study. Birth. 2005; 32:312-317. doi:10.1111/j. 0730-7659.2005.00389.x. [PubMed: 16336373]

Thorne, S. Interpretive description. Walnut Creek, CA: Left Coast Press; 2008.

Thorne, S.; Reimer-Kirkham, S.; O'Flynn-Magee, K. The analytic challenge in interpretive description. International Journal of Qualitative Methods. 2004. Retrieved from http://www.ualberta.ca/ iiqm/backissues/3_1/pdf/thorneetal.html

van den Hoonaard DK. Moving toward a three-way intersection in translational research: A sociological perspective. Qualitative Health Research. 2009; 19:1783-1787. doi: 10.1177/1049732309354998. [PubMed: 19949226]

Walker D, Worrell R. Promoting healthy pregnancies through perinatal groups: A comparison of CenteringPregnancy group prenatal care and childbirth education classes. Journal of Perinatal Education. 2008; 17(1):27-34. doi:10.1624/105812408x267934. [PubMed: 19119331]

Yalom, I. The theory and practice of group psychology. New York: Basic Books; 1995. 


\section{Biography}

Gina Novick, PhD, CNM, is a postdoctoral fellow at the Yale School of Nursing in New Haven, Connecticut, USA.

Lois S. Sadler, PhD, RN, PNP-BC, is an associate professor at the Yale School of Nursing and the Yale Child Study Center in New Haven, Connecticut, USA.

Holly Powell Kennedy, PhD, CNM, FACNM, FAAN, is the Helen Varney Professor of Midwifery at the Yale School of Nursing in New Haven, Connecticut, USA.

Sally S. Cohen, PhD, RN, FAAN, is an associate professor and senior fellow at the Robert Wood Johnson Center for Health Policy at the University of New Mexico College of Nursing, Albuquerque, New Mexico, USA.

Nora E. Groce, $\mathrm{PhD}$, is the Leonard Cheshire Chair and director of the Leonard Cheshire Centre for Disability and Inclusive Development at University College London, London, United Kingdom,

Kathleen A. Knafl, PhD, FAAN, is the Frances Hill Fox Distinguished Professor and associate dean for research at the University of North Carolina at Chapel Hill, Chapel Hill, North Carolina, USA. 